\title{
Letter to the Editor regarding the article 'ER stress-related protein, CHOP, may serve as a biomarker of mechanical asphyxia: a primary study' by Hu and colleagues
}

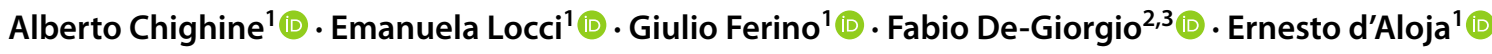

Received: 8 February 2022 / Accepted: 23 February 2022 / Published online: 1 March 2022

(c) The Author(s) 2022

We read with interest the article recently published by $\mathrm{Hu}$ and colleagues [1].

Basing on growing evidence linking cellular hypoxia induced by mechanical asphyxia to mitochondrial disfunction, the authors proposed a mitochondria-related protein — namely C/EBP Homologous Protein (CHOP) - as a potential biomarker of asphyxial deaths at very early post mortem intervals.

The tissue-specific expression of this protein - together with the quantification of several end-products of energetic metabolism (adenosine triphosphate, ATP; reactive oxygen products, ROS; mitochondrial membrane potential, MMP) - has been studied in both cell and rodent model, and even in human heart and in brain tissues.

A correlation between the mechanism of death and the expression of CHOP has been highlighted.

These findings objectivize the foreseeable mechanism of damage, and death, during mechanical asphyxia, mainly represented by the irreversible impairment of the cellular energetic powerhouse: mitochondria.

Although on a different perspective, evidence of mitochondrial dysfunction and impairment was already provided by our group while investigating, through a metabolomic approach, a homogeneous animal model of cardiac arrest (CA) [2].

In our design of experiment, one of the two investigated arms reproduces indeed a CA secondary to a pure hypoxic/

Alberto Chighine

al.chighine@gmail.com

1 Department of Medical Sciences and Public Health, Section of Legal Medicine, University of Cagliari, Cagliari, Italy

2 Department of Health Surveillance and Bioethics, Section of Legal Medicine, Catholic University of Rome, Rome, Italy

3 Fondazione Policlinico Universitario A. Gemelli IRCCS, Rome, Italy anoxic insult, obtained by clamping the trachea of landrace pigs.

Despite the experiment was designed, and conducted, with a prevalent clinical interest, the minute-by-minute plasma sampling precisely addresses modifications in the metabolome trajectories of animals experiencing CA secondary to asphyxial mechanism. The results allowed us to distinguish them from those experiencing a CA by ventricular fibrillation.

The identified metabolome modifications suggest a severe impairment of the mitochondrial tricarboxylic acid (TCA) cycle, mainly driven by reverse activity of succinate dehydrogenase (SDH) in a poor oxygen environment, consistently with the best literature available [3].

Of greater forensic interest was the second paper published by our group [4], focused exclusively on the asphyxial phase preceding $\mathrm{CA}$, which describes metabolome modifications according to the animals' outcome (damage/no damage), providing a comparison with heart and brain histopathology and immunohistochemistry.

Microscopical approach was able to distinguish animals not recovering from CA from those who were still alive and in good health - at the end of the experiment. Such an approach was useful to identify the severity of the damage, while it was unfitted to identify its causal mechanism, sharing the two models of CA a similar histopathological final pattern of damage.

Plasma metabolome modifications, on the other hand, promptly identified TCA adaptations to mounting hypoxia towards anoxia through changes in metabolomic trajectories, mainly driven by central components of the TCA cycle (namely succinate and malate).

Succinate appears to be the key molecule during oxygen shortage, being accumulated from fumarate reduction, through the reverse activity of SDH/electron transport chain (ETC) complex II, as the final electrons acceptor (in oxygen place itself). 
Yet succinate rise embodies early sign of both ATP production necessity (as TCA cycle needs to keep working to generate ATP even in the preliminary phase of oxygen reduction) and radical oxygen species (ROS) overproduction (since, over a certain amount, succinate accumulation cannot be buffered by ETC whenever oxygen levels are restored). Furthermore, MMP changes detected by $\mathrm{Hu}$ et al. may be sustained by the well-known mitochondrial permeability transition pore (mPTP) which has been demonstrated to be formed under oxidative stress such as ROS and $\mathrm{Ca}^{2+}$ overload secondary to succinate massive increase under hypoxic/ ischemic settings [5].

This finding coherently follows the intriguing role played by plasmatic succinate, already described in literature [6], suggesting a dual signalling function according to its concentration: a pro-survival role up to certain amount and a pro-death one over a point-of-no-return, where the cellular apparatus cannot cope with the upcoming ROS burst.

Furthermore, in our experiment, a significant inter-individual variability in terms of resilience to ongoing hypoxia was highlighted, despite the limited sampling size $(n=10)$.

One of the most intriguing results from a forensic perspective was that asphyxial length before CA did not directly relate to histopathological heart and brain damages nor to poor clinical outcome, while increasing plasmatic hypoxanthine resulted the only metabolite with a time-related trend.

Although driven by succinate and malate plasmatic increase, the metabolomic profile related to asphyxial death was characterised by a wider perturbation of metabolites, which underlines an up- or down-regulation of several metabolomic pathways.

In this perspective, Hu and colleagues' data strengthen our preliminary results.

Mitochondria end-products represent the final signature of the activation/deactivation of genes, miRNAs, and proteins, and all of them may be implemented as biomarkers in forensic caseworks whenever dealing with asphyxial deaths.

Forensic community should be encouraged to address this paramount issue in forensic pathology by a cooperative attempt to look at this complex biological phenomenon by a different point of view.

A synoptic reading of results from the works of $\mathrm{Hu}$ et al. and those from our research group may pave the way to this multidisciplinary approach.
Open Access This article is licensed under a Creative Commons Attribution 4.0 International License, which permits use, sharing, adaptation, distribution and reproduction in any medium or format, as long as you give appropriate credit to the original author(s) and the source, provide a link to the Creative Commons licence, and indicate if changes were made. The images or other third party material in this article are included in the article's Creative Commons licence, unless indicated otherwise in a credit line to the material. If material is not included in the article's Creative Commons licence and your intended use is not permitted by statutory regulation or exceeds the permitted use, you will need to obtain permission directly from the copyright holder. To view a copy of this licence, visit http://creativecommons.org/licenses/by/4.0/.

\section{References}

1. Hu Y, Tian L, Ma K, Han L, Li W, Hu L, Fei G, Zhang T, Yu D, Xu L, Wang F, Xiao B, Chen L (2022) ER stress-related protein CHOP may serve as a biomarker of mechanical asphyxia: a primary study. Int J Legal Med. https://doi.org/10.1007/ s00414-021-02770-1

2. Varvarousis D, Xanthos T, Ferino G, Noto A, Iacovidou N, Mura M, Scano P, Chalkias A, Papalois A, De-Giorgio F, Baldi A, Mura P, Staikou C, Stocchero M, Finco G, d'Aloja E, Locci E (2017) Metabolomics profiling reveals different patterns in an animal model of asphyxial and dysrhythmic cardiac arrest. Sci Rep 7:16575. https://doi.org/10.1038/s41598-017-16857-6

3. Pell VR, Chouchani ET, Murphy MP, Brookes PS, Krieg T (2016) Moving forwards by blocking back-flow: the Yin and Yang of MI therapy. Circ Res 118:898-906. https://doi.org/10.1161/CIRCR ESAHA.115.306569

4. Locci E, Chighine A, Noto A, Ferino G, Baldi A, Varvarousis D, Xanthos T, De-Giorgio F, Stocchero M, d'Aloja E (2021) Metabolomics improves the histopathological diagnosis of asphyxial deaths: an animal proof-of-concept model. Sci Rep 11:10102. https://doi.org/10.1038/s41598-021-89570-0

5. Bauer TM, Murphy E (2020) Role of mitochondrial calcium and the permeability transition pore in regulating cell death. Circ Res 126:280-293. https://doi.org/10.1161/CIRCRESAHA.119.316306

6. Murphy MP, O'Neill LAJ (2018) Krebs cycle reimagined: the emerging roles of succinate and itaconate as signal transducers. Cell 174:780-784. https://doi.org/10.1016/j.cell.2018.07.030

Publisher's note Springer Nature remains neutral with regard to jurisdictional claims in published maps and institutional affiliations. 